\title{
СОЦИОЛОГИЯ УПРАВЛЕНИЯ
}

УДК 316.354

РАРЕНКО А.А. ${ }^{*}$ УПРАВЛЕНИЕ ПЕРСОНАЛОМ В СОВРЕМЕННЫХ ОРГАНИЗАЦИЯХ: К ВОПРОСУ О ТАЛАНТАХ И ЦЕННОСТЯХ, РАЗДЕЛЯЕМЫХ СОТРУДНИКАМИ. (ОбЗОр).

DOI: $10.31249 / \mathrm{rsoc} / 2021.03 .11$

Аннотация. В обзоре в качестве одной из проблем управления персоналом рассматривается вопрос, связанный с поиском путей оптимизации деятельности современных организаций. Показано, что управление человеческими ресурсами является многоаспектным процессом, зависимым от множества факторов, в которых задействованы как личностные особенности человека, так и обстоятельства организационной среды.

Ключевые слова: персонал; организационное поведение; управление персоналом; человеческие ресурсы; талант; ценности.

RARENKO A.A. Staff management in today's organizations: talents and values shared by the personnel. (Literature review).

Abstract. The review examines problems of personnel management in today's organizations. Currently, the issue of personnel management in modern organizations is highly relevant since it is directly related to the optimization of labor. Human resource management is a multidimensional process as human organizational behavior is dependent on many factors which should include both personal characteristics of an individual and those determined by the environment.

* Раренко Андрей Алексеевич - младший научный сотрудник отдела социологии и социальной психологии Института научной информации по общественным наукам РАН. E-mail: andrejj97@rambler.ru 
Keywords: personnel; organizational behavior; personnel management; human resources; talent; values.

Для цитирования: Раренко А.А. Управление персоналом в современных организациях: к вопросу о талантах и ценностях, разделяемых сотрудниками. (Обзор) // Социальные и гуманитарные науки. Отечественная и зарубежная литература. Сер. 11: Социология. - 2021. - № 3. C. $135-142$. DOI: $10.31249 / \mathrm{rsoc} / 2021.03 .11$

Сегодня многие исследователи рассматривают талант человека как ключ к успеху организации, обращая особое внимание на существующие возможности и решения, содействующие выявлению и развитию талантов в организационной среде. Талантливые люди представляют собой особое выражение человеческого капитала организации - капитала, который играет подчас решающую роль в том, как компания определяет свою рыночную нишу и мобилизует конкурентные преимущества.

В настоящем обзоре мы обратимся к актуальным статьям на данную тему, которые были опубликованы в польском журнале Human resource management (польск. Zarządzanie zasobami ludzki$m i)$, издаваемом Институтом трудовых и социальных исследований (Варшава) при Министерстве экономического развития Польши. Публикации этого журнала отражают вызовы, с которыми сталкиваются менеджеры в современном мире; в нем рассматриваются различные вопросы управления человеческими ресурсами на макро- и микроуровнях. Миссия журнала - способствовать профессионализации и гуманизации данной сферы, освещая последние тренды, теоретические разработки и практические решения в области трудовой политики и управления персоналом.

В статье «Исследование карьерных решений для талантливых людей: таланты в организации» профессор кафедры управления человеческим капиталом Краковского экономического университета (г. Краков, Польша) Алисия Миш отмечает, что единого подхода к управлению талантами в современных организациях не сложилось [Miś, 2018]. Работ на эту тему достаточно много, но исследования проводятся чаще всего бессистемно, что не позволяет надлежащим образом выстроить типологию соответствующих феноменов. Автор, однако, пытается описать существующие типы 


\section{Управление персоналом в современных организациях: к вопросу о талантах и ценностях, разделяемых сотрудниками}

талантов в их потенциальной взаимосвязи с возможностями карьерного роста индивидов.

В разделе «Талант: его теоретическая и эмпирическая реализация» А. Миш обращается к работам теоретиков, которые определяют, что такое талант и каковы его характеристики. Все это, подчеркивает автор, необходимо для того, чтобы руководители и специалисты по кадровым вопросам могли разрабатывать портфель методов и инструментов для определения, развития и удержания талантов. Как правило, талант рассматривается как нечто тождественное высокому уровню производительности в конкретной среде. Часто говорят, что талантливая личность - это эксперт или профессионал с обширными знаниями и опытом в своей сфере. Таким образом, креативные люди, ищущие новые знания, умеющие экспериментировать с новыми навыками и информацией и добивающиеся уникальных результатов, считаются талантливыми личностями. Исследователи также придерживаются мнения, что талант - это уникальные особенности, которые отличают человека от остальных сотрудников компании, а реализуемые им функции способствуют достижению долгосрочных целей организации.

Таким образом, субъектом управления в деловом коллективе может быть человек / талант, отличающийся особыми личностными характеристиками, группа сотрудников (социальный капитал), занимающих определенные должности, или высокоэффективные сотрудники, достигающие наилучших результатов для организации при тех или иных условиях. Каждый из перечисленных выше подходов может соответствовать определенной организационной деятельности, направленной на удержание и развитие талантов. То, как понимается талант, влияет на выбор конкретного решения. Первоначальное восприятие проблемы было сосредоточено в основном на следующей дихотомии: талант как врожденный дар и талант как приобретенная ценность. Однако, отмечает автор статьи, такое понимание таланта полностью игнорирует другие потенциальные аспекты, которые имеют решающее значение для управления талантами.

Во втором разделе «Карьера: теоретический и практический диапазон концепции» рассматриваются основные положения теории карьеры с точки зрения управления талантами. Карьера при 
этом определяется как накопление профессионального опыта на протяжении всей производственной жизни человека.

Среди новых концепций карьеры наиболее широко описаны «безграничная карьера», «многогранная карьера» и «калейдоскопическая карьера».

Люди, отвечающие типу «безграничной карьеры», демонстрируют как психологическую, так и физическую подвижность на рынках труда. Они имеют определенные ожидания в отношении опыта работы, который они хотят получить. Характерно, что упор делается как на областях, связанных с работой, так и на других сферах жизни. Такие таланты создают карьеру «на своих условиях».

В «многогранной карьере» развитие происходит в соответствии с личностными ценностями, убеждениями и целями. «Многогранный человек» свободно выбирает тип карьеры; у него своя система измерения успеха. Планы и цели таких людей систематически модифицируются в зависимости от меняющейся среды.

«Калейдоскопическая карьера» подчеркивает гендерные различия на рынке труда. Женщины, как правило, вносят несущественные изменения в свою карьеру, в то время как мужчины меняют организации, но продолжают двигаться в однажды избранном направлении карьерного пути. Работники этого типа оценивают доступные варианты и возможности, чтобы выбрать те, которые лучше всего соответствуют их ожиданиям, шансам и ограничениям.

Разные типы таланта предпочитают разные виды карьерного роста. Так, «гуманитарный» тип таланта чаще всего связан с «безграничной карьерой», соревновательный тип таланта подходит для многогранной карьеры, элитарный тип соответствует предпринимательской деятельности и находит свое отражение в калейдоскопическом типе карьеры. Для большинства типов талантов должность не является единственным или наиболее важным фактором.

В третьем разделе рассматриваются условия создания карьерных перспектив для талантливых сотрудников. Управление карьерой талантливых сотрудников относится к кадровой функции организации. Задачи и действия, связанные с таким менеджментом, касаются всех сотрудников и являются результатом реализуемой в организации стратегии управления человеческими ресурсами. Талантливые работники составляют особую группу ввиду их 
ценности для организации. При этом организация может следовать одной из двух стратегий - работать с небольшими группами талантливых людей или привлекать таланты и развивать их.

Вопрос об управлении талантами рассматривает в своей статье «Глобальное управление талантами: текущее состояние исследований и тенденций» доцент кафедры управления человеческим капиталом Краковского экономического университета (г. Краков, Польша) Иоанна Пургал-Попела [Purgat-Popiela, 2018]. Сегодня, подчеркивает автор, проблема управления талантами особенно актуальна для многонациональных организаций, работающих в высококонкурентной деловой среде и вынужденных привлекать работников на нескольких национальных рынках труда. Статья представляет собой попытку определить состояние текущего глобального управления талантами (global talent management, GTM), опираясь на обзор литературы в области международного управления человеческими ресурсами (international human resource management, IHRM). Для анализа GTM исследованы базы данных EBSCO, EMERALD, JSTOR, SCIENCE DIRECT и SCOPUS, pacсмотрена выборка из 74 работ, осуществлен их контент-анализ. Выявлено, что до 2005 г. по рассматриваемой теме было опубликовано незначительное число статей, тогда как после 2010 г. наблюдается резкий рост интереса к тематике GTM. Начиная с 1993 г. все чаще подчеркивается стратегическое значение вопросов планирования и подготовки профессиональных менеджеров. Исследователи отмечают разнообразие талантов, которые должны определять выбор соответствующих стратегий и организационных практик.

Здесь обозначились различные подходы к теории и практике «глобального управления талантами». Самые ранние и одновременно наиболее распространенные исследовательские проблемы относятся к интеграции GTM с корпоративной стратегией, ее глобальной эффективностью, факторами, определяющими ее результаты, вопросы разрешения противоречий между глобальной интеграцией организации и ее местной адаптацией в управлении талантами. Заметно постепенное изменение аналитических подходов. Фокус смещается с поиска наиболее эффективной практики управления талантами к более широкому кругу проблем стратегического развития корпораций. 
Резюмируя все вышесказанное, автор отмечает, что управление талантами - это относительно молодая и динамично развивающаяся область исследований. В целом эволюция концепции GTM движется в сторону многоаспектного и многомерного подхода, но его форма остается не вполне определенной и требует углубленного обсуждения в академическом сообществе. Тем не менее существующие наработки, несомненно, представляют собой ценную отправную точку для дальнейших исследований и анализа множества интересных аспектов глобального управления талантами.

Одним из важных аспектов управления талантами является вопрос о корпоративных ценностях. Его в своей статье «Ценности, объединяющие поколения на рабочем месте» затрагивает Марта Млокосевич, доцент кафедры управления человеческим капиталом факультета экономики и менеджмента Щецинского университета (г. Щецин, Польша) [Młokosiewicz, 2019]. Автор отмечает, что в настоящее время на рынке труда работают четыре поколения. По этой причине управление коллективами сотрудников из разных поколений стало серьезной проблемой для работодателей. Статья имеет своей целью выявление ценностей, объединяющих разные поколения. В основном изучаются отношения работников в Польше. Анализируются вторичные данные, полученные в ходе анализа специальной литературы, а также отчеты, опубликованные консалтинговыми компаниями.

По словам Млокосевич, многочисленные исследования показывают, что сотрудники, принадлежащие к разным поколениям и испытавшие влияние различных социально-экономических и политических условий, имеют разные потребности и ожидания. Четыре поколения, присутствующие сегодня на рынке труда, исследователи определяют следующим образом: пожилые работники, «беби-бумеры», «поколение Y» и «поколение Z». Поколение «пожилых людей» (также определяемых как «строители», «ветераны», «традиционалисты» и «silent generation») характеризуется твердой приверженностью к работе, лояльным отношением к работодателю, чувством долга, ответственностью, преданностью делу, дисциплиной. Поскольку бо́льшая часть этого поколения уже находится за пределами рынка труда, лишь 0,2\% из них активны в карьерном отношении. «Беби-бумеры», относящиеся к послевоенному демографическому пику; участвовали в крупных политиче- 


\section{Управление персоналом в современных организациях: к вопросу о талантах и ценностях, разделяемых сотрудниками}

ских и социально-экономических преобразованиях. Они достаточно лояльны по отношению к работодателю, готовы принять установленные правила и не стремятся к конкуренции. Работники, принадлежащие к «поколению Х», выросли во время экономического кризиса (1970-е годы) и перестройки экономики. Они с достаточной сознательностью относятся к работе, существующим нормам и правилам и склонны самостоятельно принимать решения. «Поколение Y» (так называемые миллениалы) родилось в период демографического пика 1980-х годов и выросло в эпоху демократизации, рыночных реформ, глобализации и неограниченного доступа к Интернету. Для них характерны бо́льшая гибкость, мобильность и готовность к изменениям, но менее важно долгосрочное сотрудничество с организацией. «Поколение $\mathrm{Z}$ » также относят к «миллениалам». Они только выходят на рынок труда и рассматриваются как вариант поколения Ү. Как и поколение Y, они мобильны и склонны к командной работе, переменам, новым методам работы. Кроме того, согласно опросам, эта генерация «нетерпелива», не мыслит свою жизнь без Интернета и придает большее значение высоким доходам по сравнению с поколением Ү. Такие ценности, как признание и уважение, личностное развитие, ум, трудолюбие, надежность, лояльность к работодателю или доверие, для поколения $\mathrm{Z}$ менее важны.

Произведенный автором статьи анализ вторичных данных позволил выделить черты сходства между всеми четырьмя поколениями работников в отношении ценностей. Выяснилось, что все поколения разделяют следующие ценности: ответственность, надежность, соблюдение сроков работы, пунктуальность и «полезность другим». Что касается ценностей индивидуального характера, поколения различаются по балансу взглядов на работу и жизнь в целом, личностное развитие и самоактуализацию. Что касается межличностных отношений, все четыре поколения считают важными следующие ценности: хорошая рабочая атмосфера, сотрудничество и удовлетворительные взаимоотношения с коллегами, независимость, самостоятельность, доверие, признание и признательность. Самое молодое поколение сотрудников связывает удовлетворенность работой с «наличием интересной работы». Среди других важных ценностей, в большей или меньшей степени характерных для всех поколений, хорошая организация труда в коллек- 
тиве и экономическая безопасность (стабильная занятость и достаточно высокая заработная плата). Старшие поколения придают большее значение долгосрочной экономической безопасности, в то время как более молодые ценят гибкость и возможность изменений.

Автор статьи подчеркивает, что ценности, характерные для организации, напрямую влияют на то, как она функционирует. Чтобы ценности стали эффективным инструментом управления, их необходимо внедрять во все сферы организационного функционирования: управление персоналом, продуктами и процессами. Следовательно, организации следует сознательно определять ценности, которые ей необходимо продвигать.

Обобщая сказанное в анализируемых материалах, подчеркнем, что сегодня управление персоналом организаций должно быть направлено на соблюдение баланса между интересами всего коллектива и отдельных его представителей. Только в этом случае организация будет функционировать слаженно и выполнять поставленные перед ней задачи.

\section{Список литературы}

Miś A. Exploring career solutions for talented individuals : talents in an organization // Human resource management $=$ Zarzadzanie zasobami ludzkimi. -2018 . N 6. - P. 51-65.

Młokosiewicz M. Values integrating generations in the workplace // Human resource management $=$ Zarzadzanie zasobami ludzkimi $-2019 .-$ N 6. - P. 89-101.

Purgat-Popiela J. Global talent management : current state of research and trends // Human resource management $=$ Zarzadzanie zasobami ludzkimi. -2018 . N 6. - P. 13-28. 